\title{
Brief history of the flat glass patent - Sixty years of the float process
}

\author{
Marcio Luis Ferreira Nascimento ${ }^{a, b}$ \\ ${ }^{a}$ Vitreous Materials Lab, Institute of Humanities, Arts and Sciences, Federal University of Bahia, Rua Barão de Jeremoabo s/n, Idioms Center Pavilion (PAF IV), \\ Ondina University Campus, 40170-115 Salvador, Bahia, Brazil \\ ${ }^{\mathrm{b}}$ PROTEC/PEI - Postgraduate Program in Industrial Engineering, Department of Chemical Engineering, Polytechnic School, Federal University of Bahia, \\ Rua Aristides Novis 2, Federação, 40210-630 Salvador, Bahia, Brazil
}

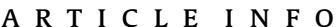

\section{Article history:}

Available online 4 July 2014

\section{Keywords:}

Glass

Flat

Float

Patent

History

Technology

Pilkington

\begin{abstract}
A B S T R A C T
This paper deals with one of the single most important innovations made in Great Britain since World War II. It is certainly one of the greatest process inventions of the twentieth century. The float process is one of the most widely used methods for flat glass manufacturing as it ensures security, high quality and productivity. From a historical point this innovation was the beginning of a revolutionary change in the mass production of flat glass for the building and automotive sectors. More specifically this innovation eliminates the traditional operations of rolling, grinding and polishing the glass surface while creating a high quality and inexpensive flat glass product. The first patent was applied for on December 10th, 1953 by Pilkington and Bickerstaff. This paper presents a brief discussion from the 1960s in a historical perspective about this amazing discovery and the main patents related to it. More than 23,900 patents using the term "flat glass" have been filed around the world, according to the European Patent Office databases. These numbers just continue to grow as do total sales worldwide. Looking for titles using flat glass, we found 2,409 patents filed. Curiously, for the same period 1,131 patents were published with float glass in the title and just 3,995 with the term in the title or abstract. So, statistically, there are more published patents using the term 'flat' than 'float' glass process.
\end{abstract}

(c) 2014 Elsevier Ltd. All rights reserved.

\section{Introduction}

From the stained glass windows of medieval churches to the Renaissance monopoly of Venetian mirror makers, flat glass has brought us protection from our environment, while also reflecting its beauty. As pointed out by Bricknell, "the prime quality of glass is that it 'seems' invisible. The less you are conscious of the glass itself (rather than its color or coating), in a window, a car windscreen or a mirror, the more valuable it is" [1].

Through the ages there have been two basic methods of forming flat glass: the window glass and the plate glass processes [2]. For centuries flat glass has been produced by blowing or by casting. In fact, the very first flat glass process was patented in March 22nd, 1848 by the English engineer Henry Bessemer (1813-1898) under number 12,101. Fig. 1 presents the manufacturing of Bessemer's process [3]. He was the first to attempt a continuous ribbon of flat glass by forming the ribbon between rollers, but it was not commercially successful. He also made some improvements to such a process which was published on the 17th February 1848 [4].

E-mail address: mlfn@ufba.br.

URL: http://www.lamav.ufba.br, http://www.protec.ufba.br
Float glass was later patented in the United States by two Americans: William E. Heal in 1902 - US patent 710,357 [5], and again in 1925 by Halbert Hitchcock - US patent 1,564,240 [6]. In the early 1900's, Emile Fourcault (1862-1919) [7,8] in Belgium and independently Irving Colburn (1861-1917) [9] in the USA invented the technique of producing a continuous ribbon of glass which still involved the glass being drawn through cooled rollers to produce a 'fire-finished' product. Briefly, in the Fourcault process [8] the glass was drawn vertically in a ribbon from a bath of molten glass. The final glass surface was achieved by letting the glass surface cool down on its own without contact while still soft. However, some distortions, irregularities and inhomogeneities suitable to this particular process would appear, mainly as the result of small differences in viscosity due to chemical or even thermal variations. The main goal of glass i.e. to be flawless, perfectly flat, totally uniform, and free from any distortion or contamination was not reached by these old processes. Up to the early 1950s before the advent of the float process, perfect results were rare and very expensive. Pilkington reported glass wastage amounting to $20 \%$ of total production at the time [2].

Sir Alastair Pilkington was born Lionel Alexander Bethune Pilkington (1920-1995) in Calcutta, India, where his father was employed at the time. According to the New York Times (NYT) 


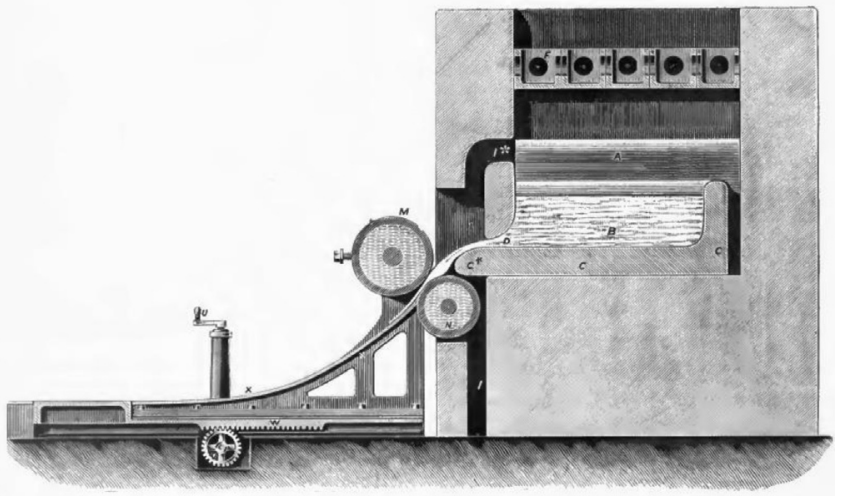

Fig. 1. Bessemer method of rolling sheet glass (1848) [3]. This mechanism is the first attempt to make a continuous ribbon of flat glass by forming the ribbon between rollers.

obituary [10], he later chose Alastair as the name he wished to be known by. He studied at Cambridge University in 1938, majoring in mechanical engineering. His studies were interrupted by the outbreak of World War II. He joined the company of Pilkington Brothers Ltd in 1947 after graduating from Cambridge and by 1953 was a member of the board. In the late 1950's, he pressed the company to continue investing in the float process, despite enormous technical difficulties. Some of these were overcome as we will see below. He developed the world's first commercially successful manufacture of high quality flat glass using their float glass process.

In 1952 Alastair Pilkington conceived the idea of forming a ribbon of glass by floating the melted raw materials at high temperature over a bath of molten tin (Fig. 2). According to The Telegraph [11], it is said that one evening in that year Pilkington had the idea of float glass when he was washing dishes at home. He was fascinated by the sight of a plate floating on water and wondered whether the principle could be applied to glass making [11]. Thus he daydreamed as he watched a bar of soap float in the greasy water, visualizing glass floating like a bar of soap. It was probably the way he suddenly conceived this idea that revolutionized the glass industry. In 1954 there was a pilot plant working [2] and the first British patent (GB 769,692 [12]) was published, but it took seven years and more than $£ 7$ million ( $£ 80$ million in today's money - according to Pilkington Company History [2]) to develop the full process. According to US patent 2,911,759 [13], applied for one year later, the ribbon is held in a chemically controlled atmosphere at high enough temperature for a long enough time for the irregularities to melt out and for the surfaces to become flat and parallel [2]. Because the surface of molten tin is flat (melting point at $231.9^{\circ} \mathrm{C}$ ), the glass is also flat - and operates from its melt at around $1,200{ }^{\circ} \mathrm{C}$ to near $600{ }^{\circ} \mathrm{C}$, when it is still a supercooled liquid, turning to glass a few Celsius degrees below. It is important to note here that the density of tin is greater than that of glass at the same temperature, and due to buoyancy an upward force exerted by tin opposes the weight of the flat glass. The ribbon is continuously cooled down while still advancing across the molten tin until the surfaces are hard enough for it to be taken out of the bath without the rollers marking the bottom surface. Therefore a uniform thickness and bright fire polished surfaces without any need for grinding or polishing are achieved. Pilkington's invention thus set out to replace the twin grinding and polishing process for making plate glass. In the event, the float glass innovation superseded not only the old process, but also the ancient sheet glass process for making ordinary windows. It was to become the universal procedure for the manufacture of high quality flat glass. The company patented the technology and licensed it to other glass producers around the world.
The process, originally able to make only $6 \mathrm{~mm}$ thick glass [2,12], now makes it as thin as $0.4 \mathrm{~mm}$ and as thick as $25 \mathrm{~mm}$ and in widths up to $3 \mathrm{~m}$ [14]. Thickness is controlled by the speed at which solidifying glass ribbon is drawn off from the bath. A modern float plant makes around $6,000 \mathrm{~km}$ of glass a year [14]. The composition of the raw materials has not changed much over the years: high quality sand, soda ash, limestone, saltcake and dolomite. This is transformed into molten glass at $1,500{ }^{\circ} \mathrm{C}$ in a melter. In brief, several processes melting, refining, homogenizing - take place simultaneously in approximately 2,000 tones of molten glass in the furnace. They occur in separate zones in a complex glass flow driven by high temperatures. It adds up to a continuous melting process, lasting as long as $50 \mathrm{~h}$, that delivers glass at $1,100{ }^{\circ} \mathrm{C}$ which is free from inclusions and bubbles, smoothly and continuously to the float bath. Finally, the glass from the melter flows gently over a refractory spout onto the mirror-like surface of molten tin, starting at $1,100{ }^{\circ} \mathrm{C}$ and leaves the float bath as a solid ribbon at $600{ }^{\circ} \mathrm{C}$. The end product is more economical and made available high class glass for shop windows, cars and mirrors free from the distortions and irregularities inherent in the products using the old manufacturing processes.

It took four years from publishing the patent to float glass becoming profitable. However, the production technique revolutionized the industry. Pilkington became the largest flat glass company in the world, mainly as a result of Sir Alastair's emphasis on using the flotation process, which produces glass with two smooth sides that do not require polishing. Such glass is now used in cars and homes and buildings all over the world [14]. However, he found it not easy to convince the company board to engage in such a project at the very beginning $[1,2]$. According to the obituary in NYT [10], he was apparently not related to the family that founded Pilkington PLC. Among its other holdings, the Pilkington Company controlled the Libbey-Owens-Ford Company, the second largest glass maker in the United States [14]. In June 2006, Nippon Sheet Glass Co., Ltd (www.nsg.com) acquired Pilkington PLC [14].

'Float' is so innovative that since 1959 it has supplanted all other techniques for forming flat glass. Alastair Pilkington played a leading role in licensing his invention throughout the world. The first foreign license went to the Pittsburgh Plate Glass Company (P.P.G.) in 1962, and this was quickly followed by manufacturers in Europe, Japan, Czechoslovakia, the former Soviet Union, Brazil and others in the USA. He was elected a Fellow of the Royal Society in 1969, knighted in 1970, and received doctorates and fellowships from 13 academic institutions, as well as numerous scientific awards. In 1978 he was awarded the Alan A. Griffith Medal and Prize by the Institute of Materials, Minerals and Mining. The Society of Glass Technology (www.sgt.org) announced in 2011 the inauguration of a prize in his honor. Thus, our goal with this work is to provide a global view of the historical trends and current status of float glass S\&T. We hope this paper will help contribute to an overall discussion on future directions for flat glass research, building on the immense framework of understanding and literature published in the field.

\section{A brief history of old glass technology}

Among the disordered systems in nature, glass belongs to the most fascinating of materials. Natural glass like the volcanic obsidian glass has been used by man from the earliest times. There is archaeological evidence for this, e.g. for carving arrowheads, knives, and other things needed for daily survival.

The first glass objects produced by man date back to about 7000 $\mathrm{BC}$ and were found in Egypt and Mesopotamia. According to Pilkington [2], Egyptians around $1500 \mathrm{BC}$ seem to have been the first people to realize what could be done with glass when heated, and the first manual of glass making appeared millennia latter. Glass 


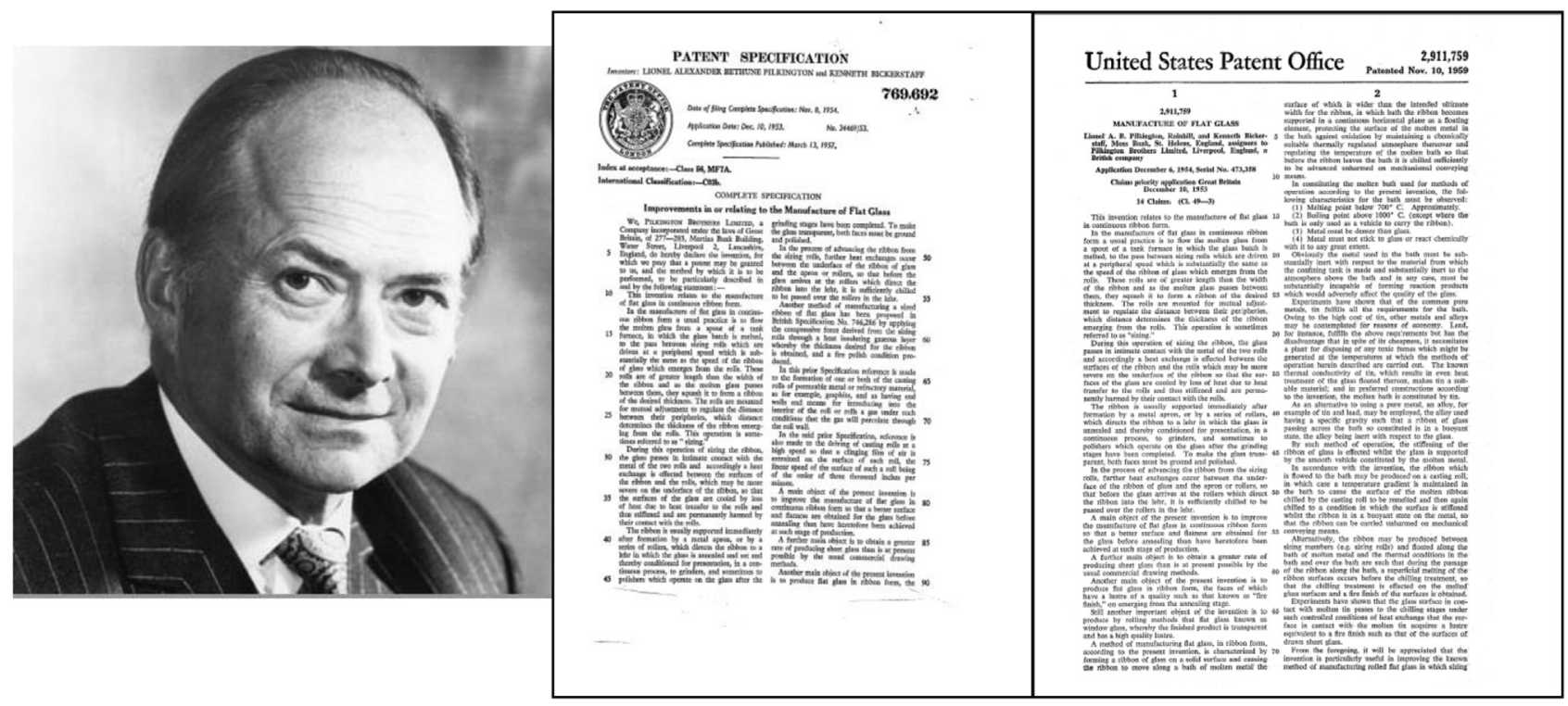

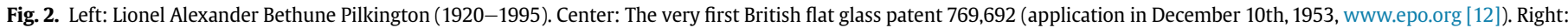
the first page of US patent 2,911,759 (www.uspto.gov) applied for on the 6th December 1954 [13].

was almost certainly discovered by accident - so the Roman historian Pliny (23-79 AD) tells us - by Phoenician traders, who apparently noticed that a clear liquid formed when the natron blocks (mixture of sodium carbonate and sodium bicarbonate) on which they placed their cooking pots melted and mixed with sand from the beach. In fact, natron was used as a cleaning product for both the home and body - blended with oil, it was an early form of soap. Glass makers probably used a recipe similar to one found in the cuneiform library of the Assyrian king Assurbanipal ( $650 \mathrm{BC}$ ): take 60 parts sand, 180 parts ash of sea plants and 5 parts lime, and you obtain glass [15]. Besides something absent (mainly a furnace working at $1,000-1,200{ }^{\circ} \mathrm{C}$ ), most of modern flat windows follow this starting raw materials composition: sand (silicon oxide), sodium, calcium and potassium carbonates.

Significant progress in glass technology came with the invention of glass blowing in the first century BC by Syrian craftsmen. This new technique greatly increased the use of glass for practical purposes. By Roman times glass-like vessels and later windows were being blown and molded, cut and engraved, painted and gilded near to perfection, and the Romans had mastered the plastic character of heat softened glass so fundamental to today's process [2], not only in Rome itself but also in their colonies.

After the fall of the Roman Empire, glass manufacturing was dispersed to isolated sites in the West, but was continued in Byzantium and later in the Middle East by the Arabs. From about 1300 on, Venice became the center of a resurgent glass industry in the West, which was able to produce the first rate glass needed for lenses and mirrors, as well as colored glass for decorative applications. The art of glass making was summarized in 1612 by Antonio Neri in 'L'Arte Vetraria'. At that time, glass makers had an extraordinarily high reputation, however, to keep the monopoly they were strictly forbidden to leave the country. Many of those who left were assassinated by hired killers, among them two glass makers that were hired by the French architect Jean-Baptiste Colbert (16191683), who made the mirrors for the famous Hall of the Mirrors in Versailles [16]. After this work, King Louis XIV founded the 'Manufacture Royale des Glaces de France', now the Saint-Gobain factory [17].

By around 1700, Venice had lost its dominant role in glass making. Glass makers were now spread all over Europe, and glass products were becoming more and more popular. The next objective was to produce better and bigger panes of flat glass and this history we briefly presented above. A final question remains, however. What in fact is glass?

\section{A brief definition of glass}

Crystals are arranged in an ordered atomic structure with mean small volumes whereas its corresponding glass presents a lack of long-range order in generally larger volumes, as schematically described in Fig. 3: a crystal (left) and its corresponding glass (right). Such a description was done as early as 1932 by Zachariasen [18]. Basically, a non-crystalline solid can be obtained in three different routes: by retaining the structural disorder of a liquid phase, by taking advantage of the disordered character of a gaseous phase, or by disrupting the order of a crystalline phase $[19,20]$.

The classical way to produce glass consists of cooling a liquid so quickly that crystallization does not have time to occur. As the temperature decreases, the continuous increase in viscosity results in a progressive freezing of the liquid to its final solidification.

To study this process more precisely, it is interesting to follow the evolution of the volume $(V)$ as a function of the temperature $(T)$ in Fig. 4. Starting with a liquid at an elevated temperature, the lowering of temperature first causes a contraction. When the point of solidification (or melting) $T_{\mathrm{m}}$ is reached two phenomena may occur - either the liquid crystallizes and a discontinuity (generally a contraction) is introduced in the curve, or crystallization is avoided and the liquid passes to a 'supercooled' state. In the latter case, the representative point follows an extension of the liquid curve which passes the temperature $T_{\mathrm{m}}$ without discontinuity. It is as if the system has "ignored" the melting point $[19,20]$.

In the first case, on completion of crystallization, as the temperature decreases the crystalline solid contracts again, the slope of the curve is now less than that of the initial liquid. In the second case, the decrease in the temperature at first causes a contraction of the supercooled liquid with a coefficient which is identical to that of the original liquid. Then, starting at a certain temperature $T_{\mathrm{g}}$, the 

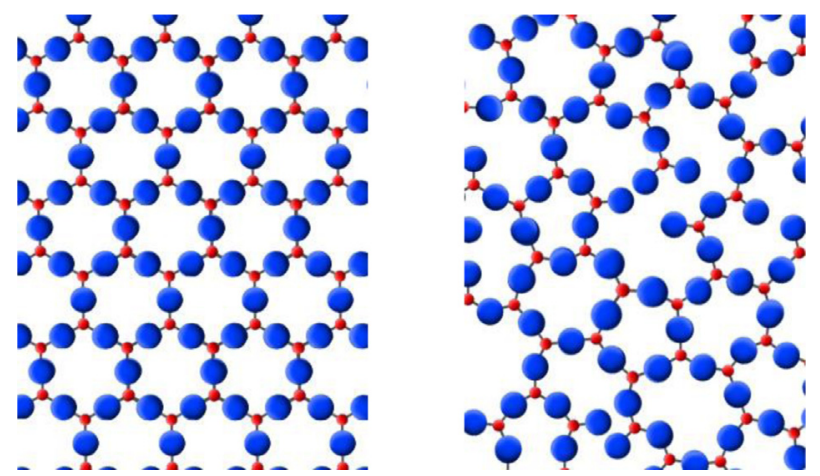

Fig. 3. Schematics of a molecular arrangement of a crystal structure (left) and its glass counterpart (right) first done by Zachariasen in 1932 [18]. Big spheres can be viewed as oxygen atoms, and smal ones silicon or boron atoms.

slope of the curve decreases to become close to that of the crystalline solid. This break in the cooling curve marks the passage from a supercooled liquid to a glass. The temperature $T_{\mathrm{g}}$ is called the transition temperature or the glass transformation temperature [19]. The viscosity of the liquid increases continuously from the melt: in the vicinity of $T_{\mathrm{m}}$, it can be as low as 0.01 poise $(\mathrm{P})$ or 1 centipoise ( $\mathrm{CP})$, which for comparison is the viscosity of water. At the so-called working point, the glass has reached the viscosity of honey $(10,000 \mathrm{cP})$, where it can be modeled most efficiently by the glass blower. With further cooling, the viscosity increases in $T_{\mathrm{g}}$ as $10^{13} \mathrm{P}[20]$. The poise is the unit of dynamic viscosity.

Glass is essentially a supercooled liquid that has failed to crystallize but, as molten glass is cooled, it passes to a temperature range (around $T_{\mathrm{g}}$ ) where nucleation and growth of crystals can occur [2]. The properties of glass, neither a true solid nor a true liquid, make it one of the most versatile materials manufactured by mankind. It has been described as another state of matter, in addition to solids, liquids and gases: a supercooled liquid, completely fluid at high temperatures, flowing less and less as it cools, until it becomes strong enough to hold its shape for centuries [19].

As a matter of curiosity, there is a myth mostly based on widespread stories that stained-glass windows of medieval cathedrals are thicker in the lower parts. Zanotto [21] estimated the time periods required for glass to flow and deform at room temperatures using calculated viscosity curves for several modern and ancient glass compositions. The conclusion is that window glass may flow

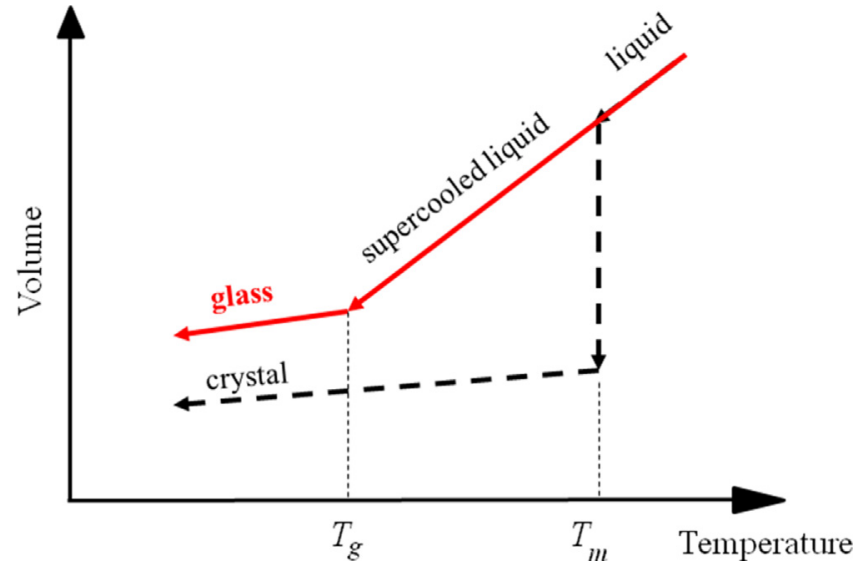

Fig. 4. Definition of the glass transition temperature $T_{\mathrm{g}}$ following the variation in the specific volume with temperature $T[19,20]$. at ambient temperature only over incredibly long times, which exceed the limits of human history, i.e. billions of years!

The possibility that some glass in cathedral windows is thicker at the bottom may be explained by the fact that ancient window glass was blown into cylinders when still molten and were split and flattened manually on an iron table. Hence, the pieces were not uniform in thickness and some lower parts could be thicker than the upper parts [22]. But one thing is certain, this innovation changed the face of architecture.

\section{Results \& discussion}

American inventors like Heal [5] and Hitchcock [6] had tried several times to achieve an improved and lower-cost process to replace the costly plate glass, but did not succeed. Sir Alistair's breakthrough, in which the molten glass was "floated" over a bath of molten tin and manipulated to achieve the required product thickness, enabled the UK-based Pilkington Glass company to lead the world market for high quality flat glass for many years, as described above.

It is important to note that Heal claimed an invention concerning "a manufacture of sheet and plate glass of any desired and continuous sheets by a new and improved method of flowing the molten glass from the melting tank into an adjacent receptacle containing melted material of a greater specific gravity than glass and causing the molten glass to float upon and spread into a continuous sheet over the surface of said melted material ..." [5]. Heal choose metals such as tin and alloys such as tin and copper. Hitchcock also claimed a similar content: "the process of continuously forming a glass ribbon or sheet, which consists in flowing the glass from a tank onto a molten bath of metal, causing it to spread out laterally and move forward over such bath ..." [6]. The same idea occurred to Fourcault $[7,8]$ and Colburn [9] in their attempts related to the "art of making sheet glass". Fourcault claimed "an apparatus for manufacturing plat glass by stretching, a tank for containing glass in a molten condition, means for drawing glass from said tank, means for cooling the glass as it is drawn upward, a float or former in said tank, a slot in said float or former, and means for forcing said float or former into the molten glass contained in said tank, for the purposes specified" [7]. Some years later, he also claimed "an apparatus for drawing a continuous sheet of glass, the combination of rollers for supplying glass at the basis of the sheet to be drawn, the rollers being dipped into the molten glass, a float having an opining therethrough in which the rollers are disposed, and means for operating the rollers" [8]. Colburn's innovation was designed to "provide a process and apparatus whereby sheet glass of uniform width and thickness may be drawn from the molten mass and subsequently annealed, after which it can be cut up into the desired sizes for the market. The invention consists in the process and apparatus for drawing the glass in a flat sheet horizontally, from the molten mass; in the mechanism for operating the drawing table either forward or backward; the means for regulating the temperature of the glass; in the construction of the glass holding apparatus or tank from which the glass is drawn; and the arrangement and combination of the various parts as more fully hereinafter described and particularly pointed out in the claims" [9].

From reading all these patents it is possible to note that the technology still needed to be perfected. All the American patents are in fact very short compared to the detailed specifications of Pilkington and Bickerstaff. They also cited the inventors Heal and Hitchcock only in the US 2,911,759 patent [13], but curiously did not cite Fourcault or Colburn. At least two reasons can explain such delay, both done by Pilkington, who wrote that [2] they "received little help from outside sources. First, because we were breaking new ground and were working beyond the frontiers of existing knowledge, 
and secondly because we could not tell people too much because of security".

In fact, Pilkington and Bickerstaff wrote more details in the first British 769,692 patent. They cited as the main objectives "to improve the manufacture of flat glass in continuous ribbon from so that a better surface and flatness are obtained for the glass before annealing than have heretofore been achieved at such stage of production" [12]. Their intention were to "obtain a greater rate of producing sheet glass than is at present possible by the usual commercial drawing methods" as well as to "have a luster of a quality such as that known as 'fire finish' (i.e. fire polished surface)". Another object of the invention was "to produce by rolling methods that flat glass known as window glass". Unlike other inventors, they cited experiments "... using tin it is essential to maintain a nonoxidising atmosphere over the bath ... a reducing gas, through a roof to the bath and to employ a roof structure adapted to maintain the gaseous atmosphere over the bath" [12,13]. Pilkington, different from previous inventors, also cited a simple model [2], where " $a$ silicone oil representing the glass, and lead nitrate solution the tin ... were able to identify ..." some specific factors involving such invention process. Other technological problems related to flat glass innovation appeared, and had not been published by previous inventors. One such was the situation involving molten glass in the bath - as it is chemically active and dissolves all refractory materials so some extent - there are discussions in both Pilkington and Bickerstaff patents about how to avoid this. In brief, there is no doubt that this single innovation eliminates the traditional operations of rolling, gridding and polishing the glass surface, while creating a high quality and inexpensive flat glass.

Concerning patents, a search in European Patent Office: Espacenet (www.epo.org) with the key words "flat glass" and "float glass" gave the following results per year considering a worldwide base (Fig. 5). In this figure it can be seen that there has been an exponential increase in patents since the first claim in 1953. One must be aware, however, that there is a common industrial practice to register several related patent applications in different countries on the same invention. Therefore, the number of patents is always greater than the actual number of unique inventions being disclosed. Searching for titles using the term flat glass, 2,409 filed patents were found. If considering title or abstract, the number reached 23,901 patents up to 2013 and this number is still increasing. Curiously, for the same period 1,131 patents were filed with the term float glass in the title and just 3,995 in the title or abstract. From Fig. 5 it is also possible to note that the term float never fully characterized such a patent, instead of the usual name "flat glass" (used in the title only).

According to the EPO database, until 2013 there were 339 "flat glass" patents in the title only and other 464 in the title or abstract with Pilkington as the applicant. Considering "float glass", there were 63 in the title only and another 185 patents in the title or abstract with the same applicant. The overall number of patents applied for by all companies until 2013 was 2,715 for "flat glass" patents in the title only and 25,889 in the title or abstract. Furthermore, 1,347 "float glass" patents in the title only and another 4,728 patents in the title or abstract with the same search terms. As examples of improvements to the flat glass process, it is possible to cite patents GB 974,635 [23], US 3,652,863 [24] and CN 1,962,506 [25], respectively filed in Britain, United States and China in different periods. The first invention relates to the manufacture of flat glass and in particular to apparatus for detecting faults (such as inclusions like crystals, scratches or even bubbles) in or on the flat glass surface [23] by means of light beams direct on or through the glass. The second invention relates to methods and apparatus for inspecting transparent ribbon or sheet glass which include the use of a laser beam, mainly analyzing the light scattering by the defects [24]. The last invention discloses a fitting material composition to manufacture low-foam content and high transmission rate glass, which consists of necessary antimonite and selectable sulfate amounts [25].

A float glass plant is designed to operate continuously 365 days per year throughout its useful life, which is typically between 10 and 15 years [14]. The global market for flat glass in 2009 was approximately 52 million metric tonnes, representing a value at the level of primary manufacture of around 22 billion Euro - i.e. glass manufactured in flat sheets (float, sheet and rolled), which may be further processed. This does not include bottles, containers, fiberglass, rods, and tubes. This industry is dominated by Europe, China and North America, which together account for over $70 \%$ of demand. China produces more than $50 \%$ of the global output of flat glass. According to an NSG report [14] this market has historically been growing in volume terms at 4 to 5 percent a year. Of the total global demand in 2009, around 29 million tonnes was for high quality float glass, 3 million tonnes for sheet

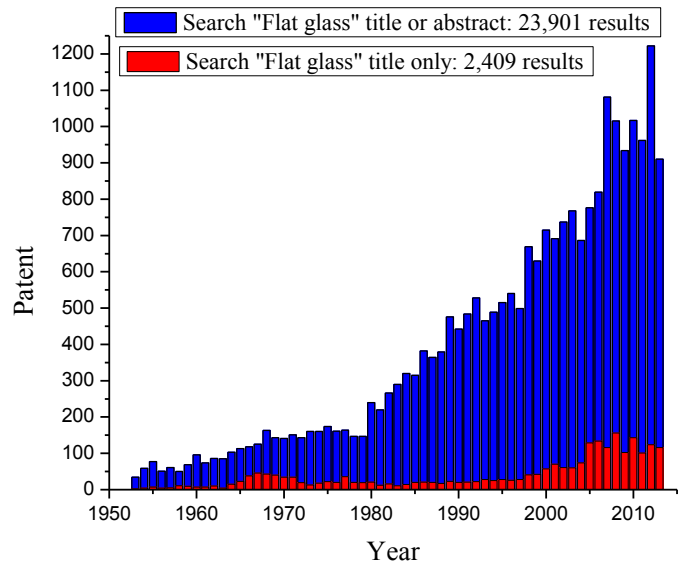

a)

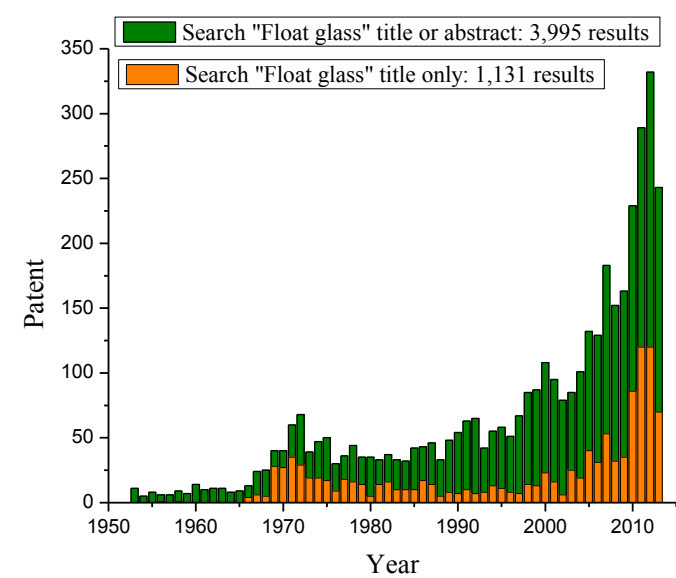

b)

Fig. 5. Frequency distribution results for patent search using (a) "Flat glass" in the title only and title or abstract; (b) search using "Float glass" in the title only and title or abstract. Data from www.epo.org. 
glass and 2 million tonnes for rolled glass. The remaining 19 million tonnes reflects demand for lower quality float, produced mainly in China - following NSG report [14]. In 2009, 40\% of float glass went into new buildings and the same proportion into building refurbishment. Approximately 5 million tonnes of the flat glass produced globally in that period was automotive glass [14].

In the 60 years since the first patent application, many patents were filed by different applicants: Asahi, Saint Gobain, Guardian, Schott, LG, Vidrio Plano de Mexico and China Southern - among others, with their respective countries: Japan, France, US, Germany, Korea, Mexico, and China. South America's market size approached 2 million tonnes in 2009, and Brazil leads in flat glass production. The float process has been licensed to more than 42 manufacturers in 30 different countries. Over 370 float lines are in operation, under construction or planned worldwide with a combined output of about 1,000,000 tonnes of glass a week. Thus, all the world's leading flat glass manufacturers have obtained licenses to use the float glass process [14].

\section{Perspectives: glass in everyday life \& near future}

Glass is one of the most used materials and is certainly one of the most versatile and adaptable. Transparency should be its best quality, as well as its chemical durability, and fragility its worst defect. Glass also has the advantage of being impermeable, easily cleaned and reusable. However, nowadays it is possible to create non-transparent or even toughened glass for specific purposes, such as metallic glasses [26] or bioglass [27] respectively. There are other useful applications of glass that have altered everyday life. To cite a few: self-cleaning glass [28]; dissolved controlling glasses [29] and vitrification of radioactive wastes.

Glass in modern life is no longer solely a material of primary technological value for architecture, transport, lighting or packing. New types of glass have been discovered and these play an increasing role in modern optics (lasers), electronics, optoelectronics [30] and energy conversion. Glass has been promoted to the rank of a noble material, not only for 'passive' but also for 'active' applications.

\section{Conclusions and final comments}

To the layman, glass is a transparent solid with good chemical durability that breaks easily. On closer inspection, however, glass constitutes a fascinating group of materials both from the fundamental and applied standpoints. It is among the most ancient materials in human history and it seems paradoxical that our knowledge of their structure is far from complete, as well as its possible applications in industry.

For example, flat glass from industrial lines can be coated, bent, shaped, laminated, and tempered. The resulting products provide year-round comfort, protect fabrics from fading, reduce energy costs, block sound transmission, improve security in vehicles, and replace walls of brick and mortar with panoramas of light and natural beauty. New mileage requirements imposed in the 1970 s also presented the automobile industry with a number of challenges - and the flat glass industry developed new products and processes to help address them. For instance, glass makers have developed new laminations that made it easier to bend flat glass so as to accommodate the car industry's more aerodynamic designs. In addition, safety glass - first manufactured for cars during the 1920s, has become lighter and thinner, with better shaping capabilities to eliminate distortion.

Today's flat glass still exhibits the ancient characteristics of form and function, while carrying us into the future as a performance platform for both practical and exotic technologies, such as flatpanel displays, liquid crystal, super-thin flat glass substrates [31], self-cleaning glass [28], mirror, solar energy and electronic information.

In this work we have presented the last great advance in the mass production of flat glass industry since World War II. It came in the 1950s with the introduction of the float glass process, where glass is floated out onto molten tin and high quality and inexpensive window glass is produced without the need for expensive rolling, grinding and polishing procedures. Pilkington's flat process was certainly one of the greatest innovations in the history of the glass industry, and one of the most extraordinary process inventions of the twentieth century. It is one of the most widely used methods for flat glass manufacturing because it ensures high excellence and high productivity for the building and automotive sectors. More than 23,900 patents have been filed around the world in these sixty years using the term "flat glass" according to the European Patent Office. These numbers just continue to grow as do total sales worldwide. Statistically, there are more published patents using the term 'flat' than 'float' glass process.

\section{Acknowledgments}

The author thanks Brazilian CNPq agency contracts 305373/ 2009-9, 479799/2010-5, 300938/2012-8 and 471546/2012-7 for financial support, and to Pilkington PLC for the photograph of L. A. B. Pilkington as shown in company website.

\section{References}

[1] Bricknell D. Float: Pilkington's Glass Revolution. Carnegie Publishing; 2012.

[2] Pilkington LAB. Review lecture. The float glass process. Proc R Soc Lond A $1969 ; 314: 1-25$

[3] Bessemer H. Sir Henry Bessemer, F. R. S. An autobiography. London: Offices of "Engineering"; 1905. p. 501.

[4] Bessemer H. The Patent journal, and inventors' magazine 94. In: Barlow C, Le Capelain P, editors. For improvements in the manufacture of plates, sheets and panes of glass; 1848. pp. 366-74.

[5] Heal WE. Manufacture of window and plate glass. US patent 710,357; 1902.

[6] Hitchcock $\mathrm{H}$. Process and apparatus for making sheet glass. US patent 1,564,240; 1925.

[7] Fourcault E. Apparatus for the manufacture of plate-glass by stretching. US patent 717,$378 ; 1902$.

[8] Fourcault E. Method of and apparatus for drawing continuous sheets of glass. US patent 941,$866 ; 1909$.

[9] Colburn IW. Process and apparatus for drawing sheet-glass. US patent $1,394,809 ; 1921$.

[10] Holusha J. Obituaries. The New York Times.. In: http://www.nytimes.com/1995/ 05/24/obituaries/alastair-pilkington-75-inventor-of-a-process-to-make-flatglass.html; May 24, 1995.

[11] Gribben R. History of 'Float' glass. The Telegraph. http://www.telegraph.co.uk/ finance/2933138/History-of-Float-glass.html; 2006.

[12] Pilkington LAB, Bickerstaff K. Improvements in or relating to the manufacture of flat glass. GB patent 769,692; 1954.

[13] Pilkington LAB, Bickerstaff K. Manufacture of flat glass. US patent 2,911,759; 1959.

[14] Pilkington and the Flat Glass Industry. Nippon Sheet Glass Co., Ltd; 2010.

[15] Bunde A, Funke K, Ingram MD. Ionic glasses: history and challenges. Solid State Ionics 1998;105:1-13.

[16] Versailles' Hall of Mirrors: http://www.chateauversailles.fr.

[17] Saint-Gobain Company: http://www.saint-gobain.com.

[18] Zachariasen WH. The atomic arrangements in glass. J Am Chem Soc 1932;54: $3841-51$.

[19] Gutzow I, Schmelzer J. The vitreous state/thermodynamics, structure, rheology and crystallization. Berlin, Heidelberg: Springer Verlag; 1995. ISBN 3-340-59087-0.

[20] Zarzycki J. Glasses and the vitreous state. Cambridge: Cambridge University Press; 1991, ISBN 0521355826.

[21] Zanotto ED. Do cathedral glasses flow? Am J Phys 1998;66:392-5.

[22] Zanotto ED, Gupta PK. Do cathedral glasses flow? Additional remarks. Am J Phys 1999;67:260-2.

[23] Benson H, Rickaby A, Beattie JR. Improvements in or relating to the detection of faults in flat glass. GB patent 974,$635 ; 1963$.

[24] Hedley GP, Derek L. Detection of faults in transparent material using lasers. US patent 3,652,863; 1972. 
[25] Li XG, Yi'an Z, Zhijin L, Liangzuo L, Weimin Y, Zhongshe X, et al. Batch composition for producing low air bubble content, high permeability glass. CN $1,962,506 ; 2006$. original document in Chinese.

[26] Faupel F, Frank W, Macht M-P, Mehrer H, Naundorf V, Rätzke K, et al. Diffusion in metallic glasses and supercooled melts. Rev Mod Phys 2003;75:237-80.

[27] Hench LL. Bioceramics. J Am Ceram Soc 1998;81:1705-28.

[28] Pilkington Activ ${ }^{\mathrm{TM}}$ : http://www.pilkingtonselfcleaningglass.co.uk.

[29] Day DE, Ehrhardt GJ. Glass microspheres. U. S. Patent 4,789,501; 1988.

[30] Tong L, Gattass RR, Ashcom JB, He S, Lou J, Shen M, et al. Subwavelength-diameter silica wires for low-loss optical wave guiding. Nature 2003;426:816-9.

[31] Peng S. Present status and internationalization prospect of China float glass technology. Bol Soc Esp Ceram V 2008;47(2):117-21.

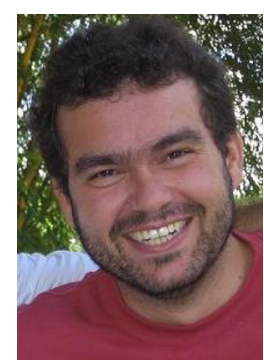

Marcio L.F. Nascimento is a physicist from University of São Paulo, Brazil, with an MSc and PhD in Condensed Matter Physics from the University of São Paulo and the Federal University of São Carlos, respectively. He is presently involved in science, technology and engineering teachings at the Department of Chemical Engineering, Polytechnic School, Federal University of Bahia, Brazil. The author has a keen interest in subjects such as materials engineering, history of sciences and in particular, mathematics for laymen. 